\title{
A atuação do designer instrucional na preparação de conteúdo para o ensino de português a distância
}

\author{
Geraldo José Rodrigues Liska*
}

\begin{abstract}
Resumo
Focamos neste artigo o ensino da língua portuguesa, especialmente o trabalho entre professor conteudista e designer instrucional, com a realização de um curso virtual sobre atualização em língua portuguesa para servidores de uma instituição pública de ensino superior. Apresentamos uma breve descrição sobre o Ambiente Virtual de Aprendizagem (AVA) escolhido, além da metodologia e dos objetivos gerais e específicos do curso. Em seguida, aprofundamo-nos sobre o design instrucional do curso, detalhando dois módulos realizados e seus recursos utilizados, com ênfase para o Mapa de Atividades e a Matriz de DI. Todas as etapas de preparação de conteúdo têm o intuito de fornecer a uma equipe de educação distância os aspectos, conteúdos, recursos e metodologia necessários para a implementação de um curso virtual. Neste trabalho, importamo-nos com a relação inegável que há entre a língua e a vida, entre o que se pretende que seja objeto de estudo linguístico e o que precisa ser ensinado. Enxergar a língua de um ponto de vista que extrapole sua constituição estruturo-gramatical é essencial para a consecução de um ensino de língua que seja mais do que informativo: que seja realmente formativo e libertador.
\end{abstract}

Palavras-chave: Design instrucional. Material didático. Educação a distância. Ensino de língua portuguesa. Ambiente Virtual de Aprendizagem.

\section{The Pratice of Instrucional Designer in The Preparation of Content For Teaching Portuguese at Distance}

\begin{abstract}
In this article we focus on teaching the Portuguese language, especially the work between content teacher and instructional designer, with the realization of a virtual course on updating in Portuguese for servers of a public institution of higher education. We present a brief description of the chosen Virtual Learning Environment (AVA), as well as the methodology and general and specific objectives of the course. Then we deepen into the instructional design of the course, detailing two modules and the resources used, with an emphasis on the Activity Map and the DI Matrix. All stages of content preparation are intended to provide to a distance education team the aspects, contents, resources and methodology required for the implementation of a virtual course. In this text, we are concerned with the undeniable relationship between language and life, between what is intended to be the object of linguistic study and what needs to be taught. To see the language from a point of view that goes beyond its structural-grammatical constitution is essential for the achievement of a language teaching that is more than informative: that it is really formative and liberating.
\end{abstract}

Keywords: Instructional design. Courseware. Distance education. Teaching of Portuguese language. Virtual Learning Environment.

Recebido: $15 / 01 / 2018$

Aceito: 04/05/2018

\footnotetext{
* Universidade Federal de Minas Gerais (UFMG). Mestre e Doutor em Estudos Linguísticos. Especialista em Design Instrucional para EaD Virtual: Tecnologias, Técnicas e Metodologias pela Universidade Federal de Itajubá (2011) e em Linguística pela Universidade Gama Filho (2010).
} 


\section{Considerações iniciais}

Tradicionalmente, tem-se vinculado à produção de material didático o designer instrucional (DI), embora essa não seja sua única função. A incorporação das tecnologias de informação e comunicação, em especial a Internet, exige uma medida sistemática de planejamento e implementação de novas estratégias didáticas e metodologias de ensino-aprendizagem. Nesse ambiente, teremos o designer instrucional, como aquele que planeja o processo de ensino e aprendizagem, incluindo atividades, estratégias, sistemas de avaliação, métodos e materiais instrucionais.

Piconez e Filatro (2004) afirmam que, amparado por tecnologias, o design instrucional admite mecanismos de efetiva contextualização, caracterizados por:

- maior personalização aos estilos e ritmos individuais de aprendizagem;

- adaptação às características institucionais e regionais;

- atualização a partir de feedback constante;

- acesso a informações e experiências externas à organização de ensino;

- possibilidade de comunicação entre os agentes do processo (professores, alunos, equipe técnica e pedagógica, comunidade);

- monitoramento automático da construção individual e coletiva de conhecimentos.

Os autores apresentam distintos estágios que os modelos convencionais de design instrucional apresentam para o planejamento do ensino:

a) análise: envolve a identificação de necessidades de aprendizagem, a definição de objetivos instrucionais e o levantamento das restrições envolvidas;

b) design e desenvolvimento: quando ocorre o planejamento da instrução e a elaboração dos materiais e produtos instrucionais;

c) implementação: quando se dá a capacitação e ambientação de docentes e alunos à proposta de design instrucional e a realização do evento ou situação de ensino-aprendizagem propriamente ditos; e por fim

d) avaliação: envolve o acompanhamento, a revisão e a manutenção do sistema proposto.

Atualmente, existem muitos desafios para o designer instrucional enfrentar a partir do próprio contexto socioeducacional. Por tratar de sistemas complexos e probabilísticos, nos quais nem tudo é previsível, precisam estar atentos à realidade do contexto, analisá-la e avaliá-la (ROMISZOWSKI, 2004). Isso amplia a responsabilidade social a fim de sempre garantir ensino de qualidade.

Como a capacitação de designers instrucionais engloba diversas áreas do conhecimento e habilidades distintas das exigidas num curso presencial, serão abordados o processo de construção de material didático, em especial um curso virtual, apresentando seus objetivos, ferramentas, estrutura e metodologia de ensino. Este trabalho objetiva contribuir para a discussão sobre o ensino da língua portuguesa na educação a distância, por meio de ambientes virtuais de aprendizagem e recursos midiáticos de ensino.

Foca-se o trabalho no ensino da língua portuguesa, especialmente entre professor conteudista e designer instrucional, executando-se o projeto para servidores de uma instituição pública de ensino superior com o curso "Atualização em língua portuguesa".

Adiante, apresentamos dois dos recursos utilizados pelo design instrucional, o mapa detalhado das atividades que foram realizadas e a matriz de DI, lembrando que ainda existe o storyboard, além da definição dos critérios de avaliação da aprendizagem, muito importantes para a consolidação do conhecimento do aluno.

Todas essas etapas têm o intuito de fornecer a uma equipe de educação a distância os aspectos, conteúdos, recursos e metodologia necessários para a implementação de um curso virtual. 


\section{A produção de material didático para a e-learning}

Denomina-se e-learning a educação a distância que se utiliza de suporte eletrônico por meio de tecnologia da informação (E-LEARNING BRASIL, 2008). Ela pode acontecer usando totalmente ou parcialmente a internet, por meio do desenvolvimento inteiro do curso pela web ou pelo estudo dos temas abordados em um CD-ROM e a disposição das avaliações on-line, com marcadores de tempo e resolução automática dos exercícios, respectivamente.

As atividades podem ser síncronas e assíncronas, conforme o tempo e o espaço para sua realização. Aquelas acontecem em tempo real, por meio da troca de mensagens em um ambiente destinado a esse fim, por exemplo, e estas permitem a comunicação entre os participantes do grupo, sem que haja necessidade de todos estarem conectados ao mesmo tempo, como a utilização de um correio eletrônico ou de fóruns de discussão.

Conforme Possoli e Cury (2009),existem os mesmos propósitos para a produção de material didático tanto virtual quanto impresso, pois: 1) os dois são criados para atender situações de ensino e aprendizagem; 2) necessitam de uma equipe multidisciplinar de profissionais para a sua produção; 3) a estrutura básica dos materiais é a mesma, pois se baseiam nas mesmas mídias. No ensino presencial, o professor medeia a sua relação com os alunos por meio do material didático. Já em algumas categorias da educação a distância, o material didático, em suas diversas mídias, é o único vínculo do aluno com o professor, como o que ocorre em cursos de e-learning, em que se utiliza Ambiente Virtual de Aprendizagem (AVA), constituídos como espaços virtuais de comunicação e aprendizagem colaborativa.

A construção de um AVA, com o uso de tecnologias computacionais, possibilita o acesso rápido à informação e à comunicação interpessoal, em qualquer lugar e tempo, contribuindo assim para o desenvolvimento de projetos em colaboração e a coordenação de diversas atividades. Esses ambientes virtuais de aprendizagem são nada mais do que sistemas computacionais disponibilizados na internet, destinados ao suporte de atividades mediadas pelas tecnologias de informação e comunicação. $\mathrm{O}$ AVA permite integração de diversas mídias, linguagens e recursos, apresenta informações de maneira organizada, nele se desenvolvem interações entre pessoas e objetos de conhecimento, elaboram-se e socializam-se produções, tendo em vista atingir determinados objetivos. As tarefas se desenvolvem no tempo, ritmo de trabalho e espaço em que cada participante se localiza, de acordo com uma intencionalidade explícita e um planejamento prévio denominado design educacional, que estabelece as atividades a serem realizadas, sendo revisto e reelaborado de forma contínua, de acordo com o andamento da atividade.

São vários os programas educacionais projetados por universidades e/ou grupos de pesquisas,

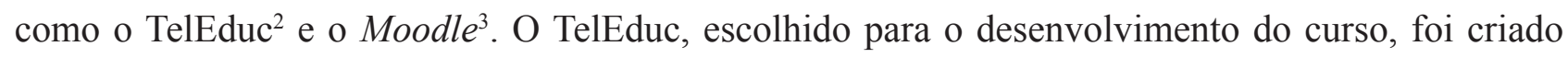
pelo Instituto de Computação da Unicamp e pode ser utilizado para atender a alunos, com a oferta de algumas disciplinas on-line dos cursos de graduação e pós-graduação, e não alunos, por meio de cursos de extensão de uma instituição de ensino superior, por exemplo.

A preparação e execução de conteúdo para um curso de e-learning requer cuidados que garantam aos alunos possibilidades de entendimento e compreensão, preservando fácil assimilação. Freitas, Loyolla e Prates (2002) ressaltam que a linguagem oferecida por esses cursos deve se diferenciar daquela utilizada nos conteúdos distribuídos por meio de impressos, bem como aqueles direcionados para a televisão e rádio. Imagens e elementos multimídias podem omitir dados, portanto, eles devem ser devidamente legendados. A clareza, objetividade e acessibilidade são as características mais importantes na linguagem oferecida por eles.

2 Mais informações podem ser obtidas em http://www.teleduc.org.br/ . Acesso em 18 jul. 2017.

3 Mais informações podem ser obtidas em https://moodle.org/?lang=pt_br . Acesso em 18 jul. 2017. 


\section{Metodologia do curso "Atualização em Língua Portuguesa”}

\subsection{Breve descrição sobre o AVA escolhido para o curso "Atualização em Língua Portuguesa"}

O AVA TelEduc fornece um conjunto de ferramentas repletas de informações e conteúdos da dinâmica do curso com recursos de comunicação. Esses recursos visam possibilitar o acompanhamento do processo de aprendizagem do aluno, além de permitir um contato constante entre o formador e os alunos do curso e entre os próprios alunos.

Ao acessar o AVA, o aluno se depara com a agenda do curso. Nela, são fornecidas as informações para o primeiro acesso:

Figura 1 - Informações para primeiro acesso ao curso ${ }^{4}$

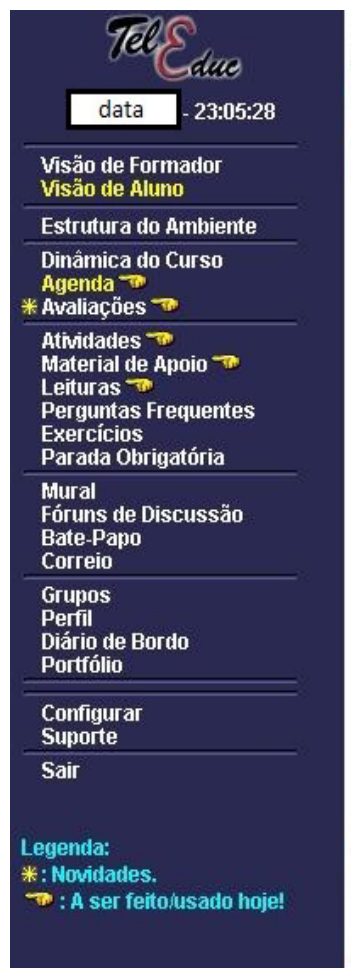

CTDI04 - Atualização em Língua Portuguesa

Agenda - Bem-vindo!!!

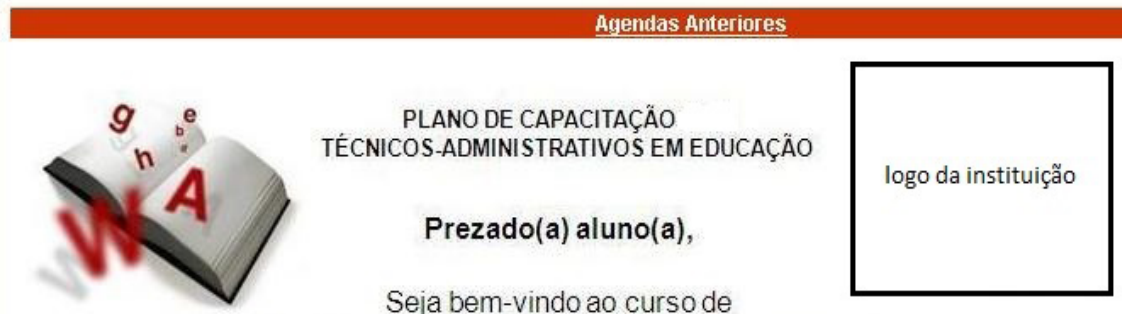

Atualização em Língua Portuguesa.

Antes de iniciar seus estudos, leia atentamente a DINÂMICA DO CURSO, disponivel no menu à esquerda, pois será seu principal instrumento no percurso de sua aprendizagem.

Clique no menu ATIVIDADES e depois em AULA 1 para darmos início ao curso.

Bons estudos! professor

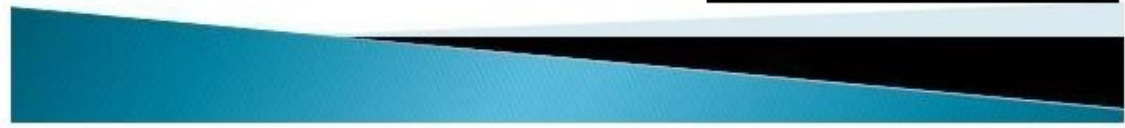

As atividades do curso foram organizadas e disponibilizadas por meio das ferramentas Atividades e Material de Apoio, as quais são diferenciadas mais conceitualmente do que computacionalmente; aquela é usada para garantir a sequência de estudos, permitindo a realização dos exercícios e avaliações gradativamente, e esta apresenta todo o conteúdo teórico midiático do qual o aluno precisará.

\subsection{Os objetivos gerais e específicos do curso}

O curso tratado neste artigo foi realizado em uma instituição federal de ensino superior, tendo como primeiro direcionamento seu Plano de Capacitação (UNIFAL-MG, 2010):

Dotar a UNIFAL-MG, através da capacitação de seus servidores Técnico-Administrativos, de uma força de trabalho qualificada em nível gerencial e técnico, para desempenhar com eficácia suas competências institucionais em perfeita sintonia com a estratégia organizacional (missão, visão de futuro e objetivos). (UNIFAL-MG, 2010).

4 http://www.ead.unifei.edu.br/\%7Eteleduc/cursos/aplic/index.php?cod_curso=1500, Acesso em 17/8/2017. 
Preocupamo-nos, portanto, em qualificar o servidor público para fazer uso da linguagem escrita de maneira adequada ao contexto formal, servindo-se especialmente dos conhecimentos sobre o acordo ortográfico e de características específicas da redação oficial (BRASIL, 2002b), como a objetividade, a clareza e a padronização estética.

Pensando em uma proposta além da memorização mecânica de regras gramaticais, buscamos, embasados nos Parâmetros Curriculares Nacionais (PCN, BRASIL, 2002a), desenvolver no aluno seu potencial crítico, sua percepção das múltiplas possibilidades de expressão linguística, sua capacitação como leitor efetivo dos mais diversos textos representativos de nossa cultura. Concordamos com os PCN que o aluno deve ter meios para ampliar e articular conhecimentos e competências que possam ser mobilizadas nas inúmeras situações de uso da língua com que se depara, tanto no trabalho (foco do curso), como na família, entre amigos e em outros contextos de socialização.

Foram objetivos específicos do curso:

- elaborar registros de linguagem pertinentes e adequados a diferentes situações comunicativas, em especial a comunicação oficial;

- considerar as diferenças entre língua oral e escrita.

- empregar mecanismos de coesão referencial (retomada pronominal, repetição, substituição lexical e elipse);

- empregar ortografia oficial do português (atentando-se para casos idiossincráticos e as palavras de frequência muito restrita);

- conhecer e empregar regras de concordância verbal e nominal.

Ao final do curso, o aluno foi capaz de:

- reconhecer a leitura e a escrita como atividades interativas de produção.

- compreender e produzir, com autonomia, diferentes gêneros de textos, com distintos objetivos e motivações.

\subsection{Metodologia do curso "Atualização em Língua Portuguesa"}

Inicialmente, foi realizada uma pesquisa de caráter qualitativo, pois foi por meio da análise das relações e das representações da sociedade que se deu o primeiro passo para a construção do curso, lembrando ainda que a experiência do designer instrucional com a sistematização progressiva do saber para o desenvolvimento do projeto é fundamental quando se trata de atender ao público-alvo com êxito.

A pesquisa de natureza exploratória se define pela seleção dos conteúdos a serem abordados no curso, tanto de maneira didática como de acordo com a legislação e as propostas e orientações curriculares nacionais, em especial aos PCN (BRASIL, 1998) e às Orientações Curriculares Nacionais (BRASIL, 2006).

Como o designer instrucional e o professor conteudista foram a mesma pessoa, a formulação, a organização, a apresentação e a prática do currículo pelos alunos fazem-se unindo os conhecimentos adquiridos com as duas experiências, pois, de um lado, como educador, sabe que deve continuar o trabalho docente a partir da bagagem de conhecimentos que os alunos adquirem ao longo de seu processo anterior de escolarização; do outro, como especialista em tecnologias, técnicas e metodologias para a educação a distância, compreende que essa bagagem pode ser trabalhada de forma interativa por meio de ferramentas assíncronas e síncronas, como fóruns de discussão e salas de bate-papo, respectivamente, contribuindo para a socialização do AVA.

Alcançar todos os alunos, ao disponibilizar o material didático sob várias formas midiáticas (arquivos de textos, imagens, vídeos, jogos eletrônicos etc.) foi uma grande preocupação na projeção do curso. Para que o curso obtivesse sucesso, foi necessário trabalhar a realidade do público em questão, focando 
os variados estilos de aprendizagem dele. Embora mesmo essas combinações sendo diferentes de uma pessoa para outra, deve-se buscar características comuns entre um grande número de participantes. Honey e Munford (apud MIRANDA e MORAIS, 2008) apresentam quatro traços distintos para as formas com as quais as pessoas lidam com a consolidação de conteúdos: pragmático, teórico, ativo e reflexivo. Pensando nisso, sugeriu-se que eles preenchessem o Questionário Honey-Alonso de Estilos de Aprendizagem ${ }^{5}$ na etapa inicial do curso, pois poderiam ser criadas atividades que exigissem esforços individuais, cultivando a autonomia, e coletivos, colaborando com a interação, reflexão e produção de ideias, tornando a busca pelo conhecimento um exercício prazeroso e contribuindo para a harmonia e o contínuo funcionamento do AVA.

Ao final de cada módulo teórico, o aluno se submetia à avaliação processual e contínua, por meio de atividades propostas e trabalhos dirigidos. Essa é a forma de descobrir o nível de aprendizado dos alunos e reconhecer se o método de ensino utilizado foi satisfatório, sempre repensando as informações e a didática com a qual foram apresentadas. Trata-se de uma ferramenta usada pelo professor para verificar o conhecimento adquirido pelo aluno após o estudo de um determinado assunto. Vale ressaltar que a avaliação dos alunos é também a avaliação do professor e do designer instrucional, pois é este o momento no qual eles devem analisar o que foi importante e sempre melhorar a forma pela qual ensinam, no caso do professor, ou a maneira como apresenta e organiza as atividades, no caso do aluno.

A pesquisa bibliográfica foi importante também para a realização de um dos objetivos do processo de análise dos dados coletados do curso: promover a inclusão de Portadores de Necessidades Especiais (PNE), visando à oportunidade para que todos os alunos se tornem leitores e escritores competentes, embora no curso em questão não tenha havido participação de PNE. Isso apenas será possível se. no ambiente onde é difundida a educação, haja a demanda e interesse pela inclusão de todos.

Para se fazer uso com eficácia das Tecnologias Assistivas e de Softwares para os portadores de necessidades educacionais especiais, consultamos a Cartilha Técnica do Modelo de Acessibilidade de Governo Eletrônico (ENAP, 2007), desenvolvendo e distribuindo as atividades da melhor forma, que atendesse as exigências das mais variadas necessidades especiais vivenciadas em situações adversas no uso do computador. Seguiram-se também, dessa cartilha, as orientações de boas práticas para a elaboração de conteúdo que permita a acessibilidade na web. Como se trata de implantação do curso, as experiências com as PNE podem resultar em importante relatório para a pesquisa experimental e participante.

\section{Design instrucional do curso}

\subsection{Técnicas, métodos e estratégias}

Os conteúdos foram definidos pelo professor de Língua Portuguesa idealizador do curso e também Designer Instrucional, responsável por tornar dinâmico o curso e, ao mesmo tempo, atender à necessidade dos alunos quanto ao conhecimento dos variados gêneros textuais, em especial os textos oficiais, e mecanismos de linguagem.

As atividades foram distribuídas de várias maneiras pelo AVA, por meio da postagem de portfólio no decorrer do curso, e contaram com a participação do aluno em fóruns de discussão, para que as ideias fossem compartilhadas e promovida a interação entre os participantes do curso. Foram disponibilizadas avaliações ao final de cada semana / módulo. O aluno não podia acumular as tarefas

5 Disponível em http://www.estilosdeaprendizaje.es/chaea/chaeagrafp2.htm . Acesso em 22/06/2017. 
e só dava início a uma nova semana após o término dos exercícios da semana anterior. Foi exigido do aluno o período necessário para a realização das atividades em dia, refletido no tempo do qual o aluno necessita para a assimilação do conhecimento, lembrando que isso é diferente de aluno para aluno. Confrontaram-se, com a prática aplicada no decorrer do curso, todos os conteúdos baseados em interpretação de textos de forma reflexiva e crítica.

A interatividade virtual entre os alunos foi feita pelas participações em fóruns de discussão e pela ferramenta correio, lembrando que a linguagem é uma atividade interativa e a interação é o principal meio para a inserção social.

\subsection{O Mapa de Atividades e uma descrição detalhada do 1 Módulo}

O curso apresentado teve duração de 30 horas e, de acordo com a definição da carga horária, foi dividido em cinco módulos (chamados de aulas no AVA), com duração de seis semanas, conforme Figura 2.

Figura 2 - Atividades do curso

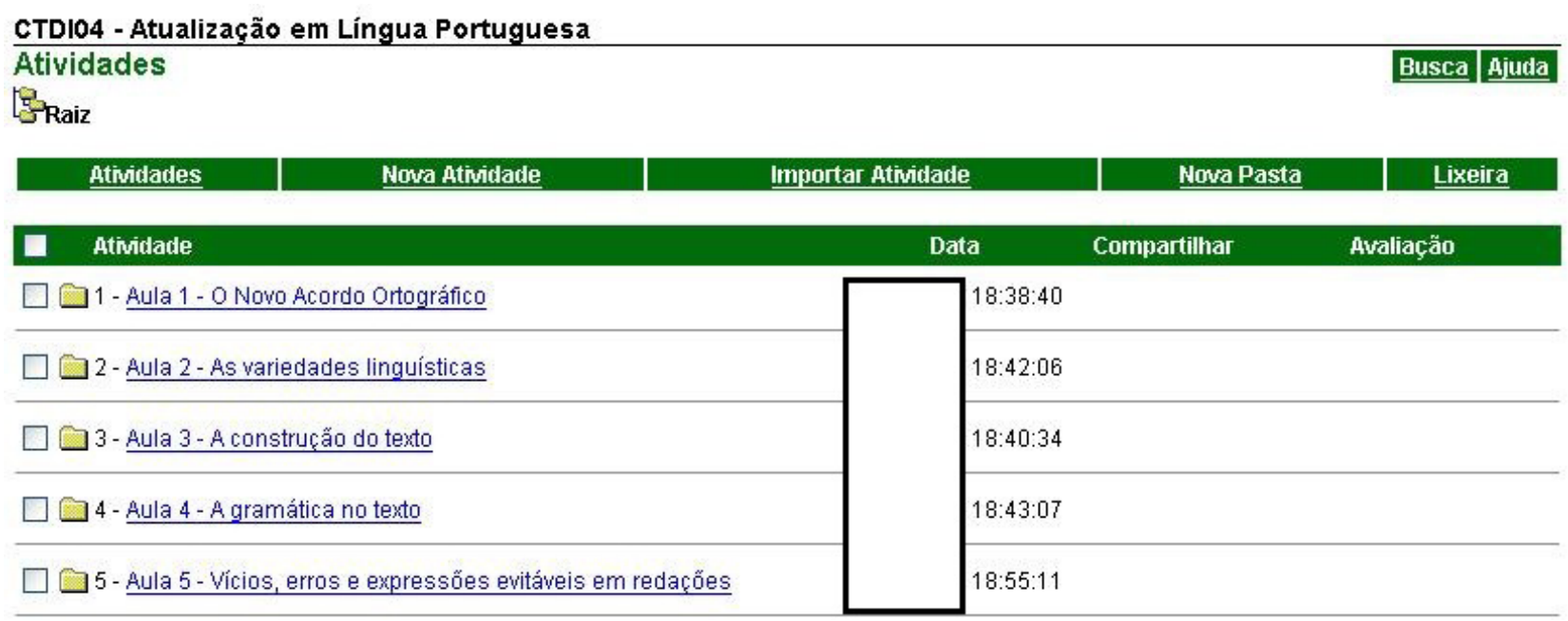

Fonte: AVA do curso "Atualização em Língua Portuguesa"

Ao clicar em cada uma das aulas, o aluno era direcionado a uma página com dois itens, um apresentava a descrição da aula e o outro tratava da avaliação dessa aula:

Figura 3 - Aula 1 - O Novo Acordo Ortográfico

CTDI04 - Atualização em Língua Portuguesa

Atividades

焉aiz $\gg$ Aula 1 - o Nowo Acordo Ortográfico

Atwidade Data

氡O Novo Acordo Ortográfico

率 $1^{2}$ Avaliaçẫo

$2: 01: 20$ $2: 36: 31$

Fonte: AVA do curso "Atualização em Língua Portuguesa" 
No primeiro módulo, foram trabalhadas as regras do novo acordo ortográfico em todas as suas 21 bases, conforme Decreto $n^{\circ}$ 6.583/2008, que promulga o Acordo Ortográfico da Língua Portuguesa, e algumas particularidades de acordo com o país em que o português é língua oficial.

Os conteúdos foram apresentados repletos de imagens e sons, com a intenção de ser lúdico e atraente. Permitiu-se que o aluno tivesse liberdade em seguir para o Material de Apoio ou testar seus prévios conhecimentos sobre o assunto com uma bateria de exercícios.

Após acessar o Material de Apoio, poderiam ser acessados infográficos sobre o acordo ortográfico, o alfabeto, as regras de acentuação, de trema e de hífen. Também teve a opção de participar do Game da Reforma Ortográfica ${ }^{6}$, onde, a cada resposta certa, avança-se uma casa, praticando o conhecimento adquirido durante a leitura dos slides.

$\mathrm{Na}$ ferramenta Leitura (de caráter complementar), foram disponibilizados cinco arquivos: o Guia Prático Michaelis da Nova Ortografia ${ }^{7}$; uma apresentação de slides organizada pela equipe da Olimpíada da Língua Portuguesa explicando resumidamente as mudanças do Novo Acordo Ortográfico; a Reforma Ortográfica contada pela Turma da Mônica, destinada àqueles que gostam de quadrinhos; uma explicação dada pela revista Abril de todas as bases nas quais estão organizados os itens do Novo Acordo Ortográfico; e o Decreto 6.583, de 29 de setembro de 2008, que promulga o Acordo Ortográfico da Língua Portuguesa.

\section{Figura 4 - Leituras - O Novo Acordo Ortográfico}

Comentário
Olá, pessoal!
Anexos estẫo vários arquivos que eu sugiro como leituras complementares em relaçấo ao Novo
Acordo Ortográfico. Isso nấo significa que a visualizaçấo deles é obrigatória, mas nunca é demais
em relaçấo ao aprendizado.
O primeiro arquivo é o Guia Prático Michaelis da Nova Ortografia, de Douglas Tufano, distribuído pela
editora Melhoramentos.
O segundo é uma apresentaçẫo de slides organizada pela equipe da Olimpíada da Língua
Portuguesa. É uma explicaçấo bem resumida sobre as mudanças do Novo Acordo Ortográfico.
Já o terceiro é destinado àqueles que adoram quadrinhos. É a Reforma Ortográfica contada pela
Turma da Mônica.
O quarto se trata de uma explicação dada pela revista Abril de todas as bases nas quais estão
organizados os ítens do Novo Acordo Ortográfico.
Por último, há o Decreto 6.583 , de 29 de setembro de 2008 , que promulga o Acordo Ortográfico da
Língua Portuguesa, assinado em Lisboa, em 16 de dezembro de 1990 .

Bons estudos!

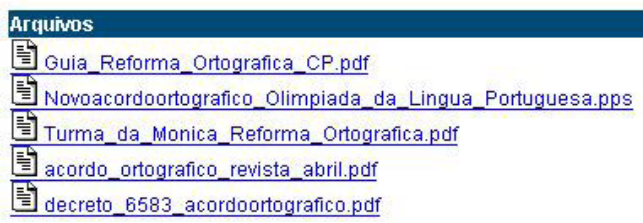

Fonte: AVA do curso "Atualização em Língua Portuguesa”

Todo esse percurso, assim como o detalhamento do curso inteiro, deve ser descrito por um Mapa de Atividades ${ }^{8}$. Nele, constarão a quantidade de aulas e de módulos do curso (e suas divisões em períodos, dias ou semanas, por exemplo), a unidade ou o tema principal de cada divisão, com suas subunidades, subtemas, os objetivos específicos de cada um, as atividades teóricas disponibilizadas em recursos / ferramentas.

6 Disponível em http://www.livroclip.com.br/livrogames/games/fmu/fmu.html, acesso em 15 maio 2017.

7 TUFANO, Douglas. Guia Prático da Nova Ortografia: saiba o que mudou na ortografia brasileira. Disponível em: http:// www.livrariamelhoramentos.com.br/Guia_Reforma_Ortografica_Melhoramentos.pdf.Acesso em: 17 jan. 2017.

8 O Mapa de Atividades do curso em questão pode ser acessado na íntegra em https://goo.gl/KQaoKn, Acesso em 15 ago 2017. 
O Mapa de Atividades é um recurso para planejamento do curso e traz informações importantes sobre as ferramentas do AVA e recursos que serão utilizados, assim como as mídias, valor e duração de cada atividade em sua respectiva aula, além dos objetivos específicos (FILATRO, 2008)

\subsection{A Matriz de DI e uma descrição detalhada do 2ํo Módulo}

Depois de elaborado o mapa de atividades pelo designer instrucional, as aulas devem ser minuciosamente detalhadas, principalmente as mais complexas, para que sejam produzidas e aplicadas corretamente pela equipe da educação a distância. Para isso, foi feito o uso da Matriz de Design Instrucional (ou Matriz de DI) ${ }^{9}$.

Segundo Filatro (2008), objetivos, atividades e conteúdos são elementos básicos do processo educacional e podem ser organizados em uma matriz que nos permite ter uma visão panorâmica de cada unidade de aprendizagem.

Com ela, podemos definir quais atividades serão necessárias para atingir os objetivos, bem como elencar quais conteúdos e ferramentas serão precisos para a realização das atividades. Podemos também estabelecer como se dará a avaliação do alcance dos objetivos. A matriz permite ainda verificar quais serão os níveis de interação entre o aluno e os conteúdos, as ferramentas, o educador e os outros alunos e que tipo de ambiente virtual será necessário para o desempenho das atividades.

Como as aulas virtuais diferem das presenciais pela interação, devem-se planejar atividades que façam do AVA também um lugar de socialização. Interatividade, assim, exige detalhamento, logo, é um exemplo a ser desenvolvido na Matriz de DI. Esta é organizada de modo a possibilitar o desenvolvimento de uma atividade:

- identificação da Atividade;

- descrição / proposta da dinâmica;

- objetivo(s);

- critérios / avaliação ;

- tipo de interação;

- prazo;

- ferramenta;

- conteúdo(s) de apoio e complementares;

- produção dos alunos / avaliação;

- feedback.

Detalhamos a segunda avaliação do projeto, apresentada na Matriz de DI do segundo módulo do curso. Nela, os alunos deveriam contar, com a ajuda de sua formação cultural e linguística, algum acontecimento que o marcou em relação a algumas palavras e expressões. Além disso, pediu-se para que, se reconhecesse o sentido de pelo menos uma delas, deveria explicá-lo.

9 A Matriz de Design Instrucional do curso em questão pode ser acessado na íntegra em https://goo.gl/tWSPq1, Acesso em 15 ago 2017. 
Figura 5 - Proposta de atividade

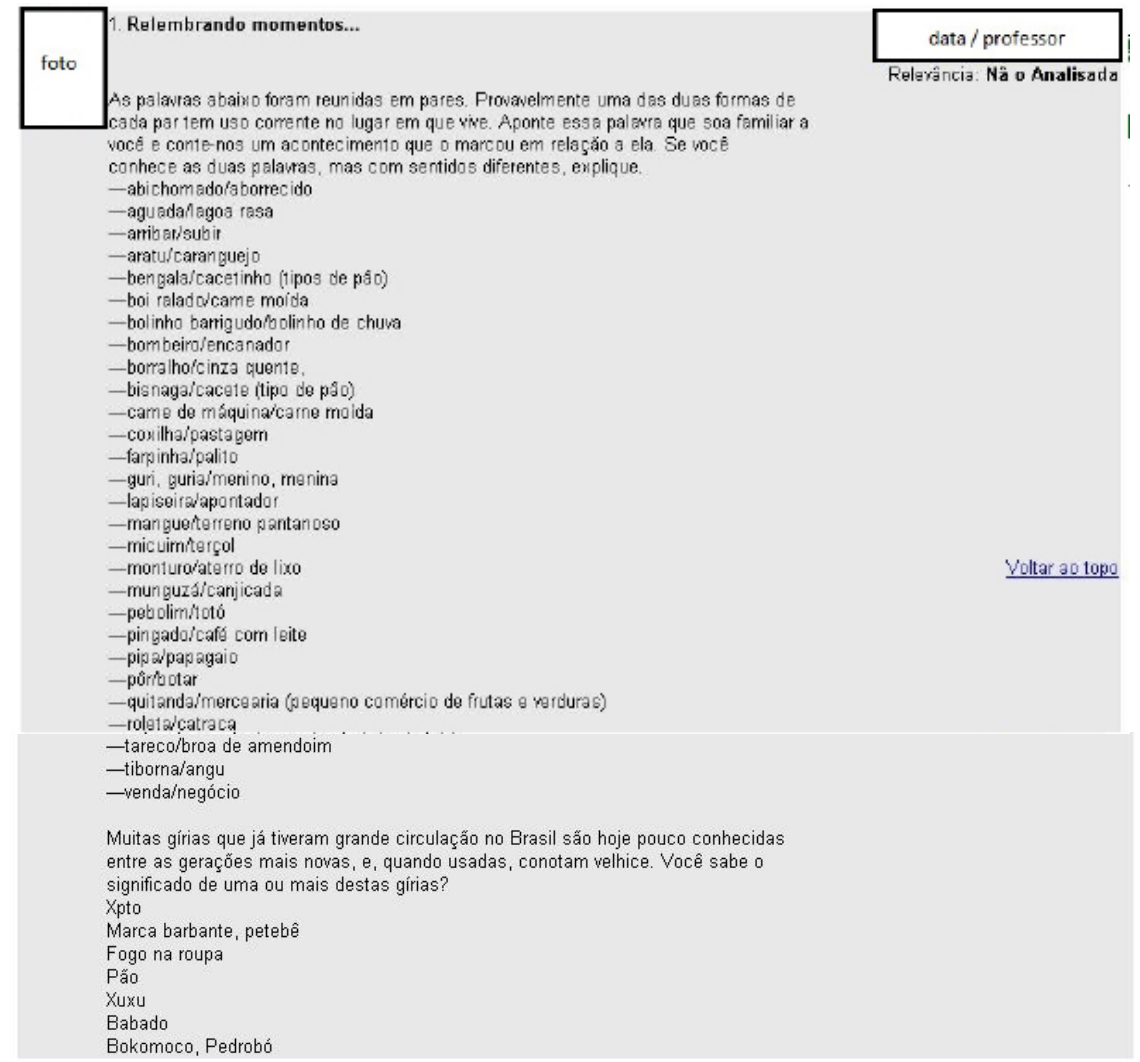

Fonte: AVA do curso "Atualização em Língua Portuguesa"

Essa atividade contou com 26 participações. Com a finalidade também de descontrair, os alunos tiveram a oportunidade de relembrar e compartilhar situações embaraçosas ou não que os levaram a compreender a existência de uma diversidade sociolinguística e cultural e que isso não deve ser objeto de preconceito linguístico, relacionando o que está 'certo' ou 'errado' na fala de coenunciadores.

A maioria dos participantes relatou experiências que tiveram em diferentes contextos de uso da língua e algumas diversidades regionais e apresentaram sentidos para palavras e expressões que já caíram em desuso.

\section{Figura 6 - Participações}

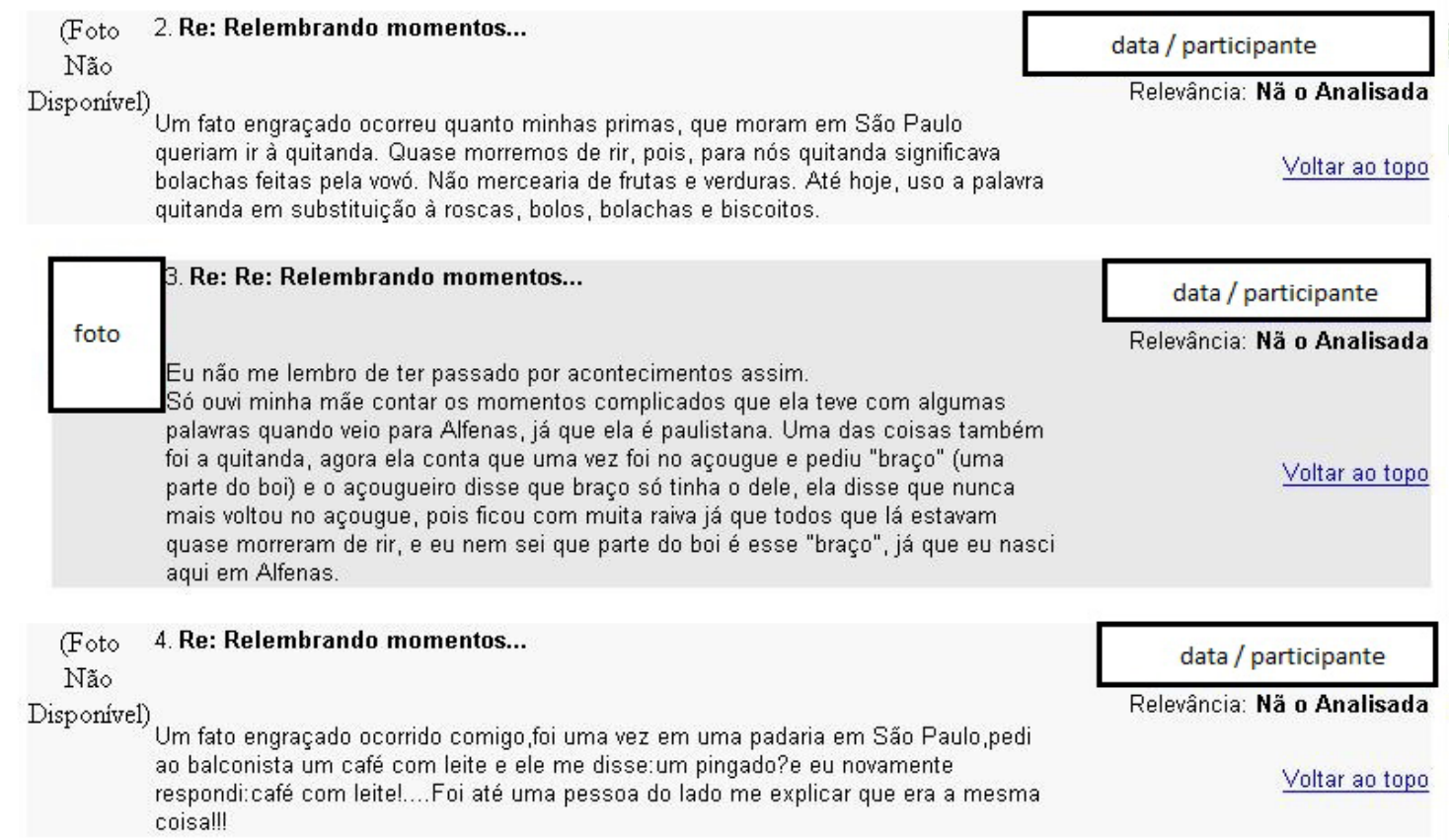



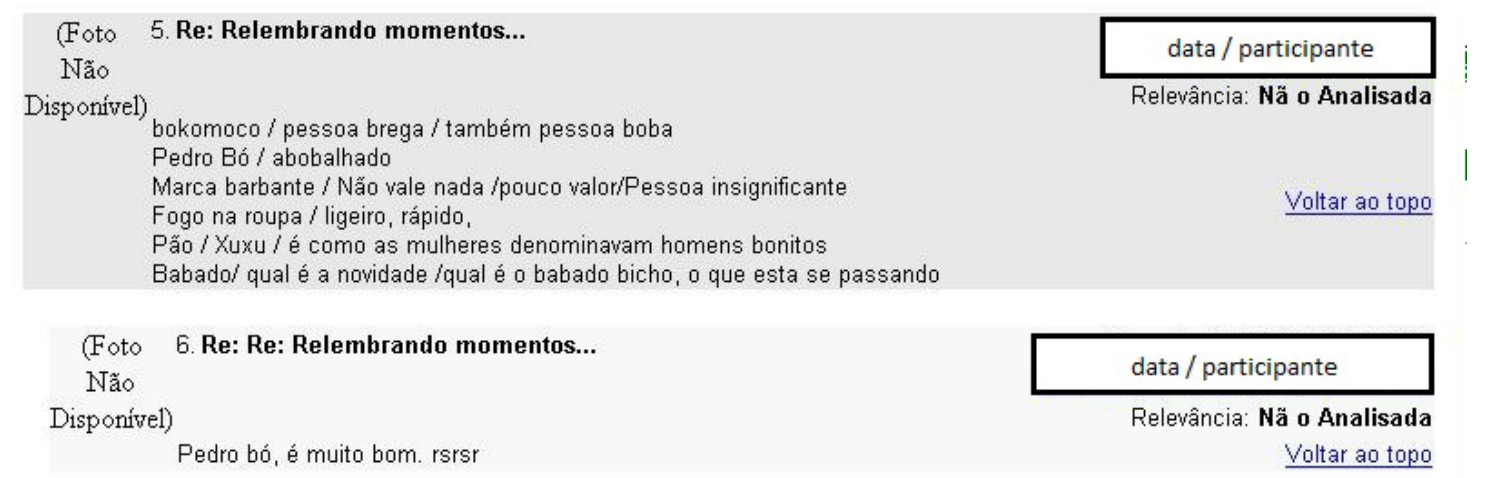

data / participante

Relevância: Nã o Analisada

Voltar ao topo

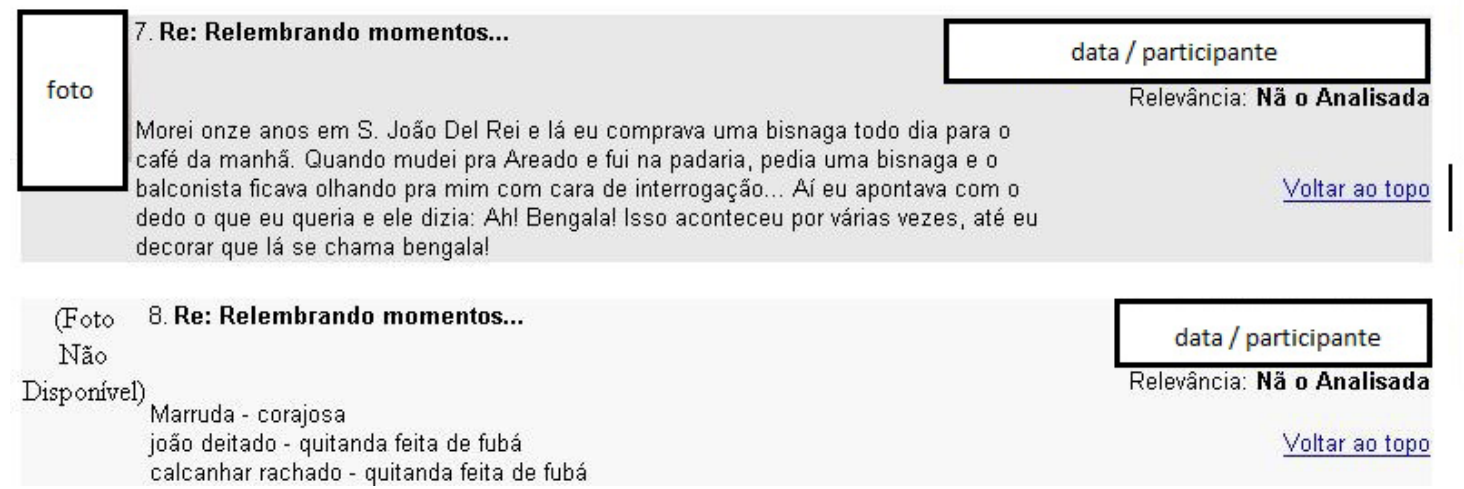

Fonte: AVA do curso "Atualização em Língua Portuguesa”

Esse módulo abordou as variantes linguísticas, visto que o estudo delas é importante para que o aluno não julgue a língua como um sistema fechado, no qual a norma (a gramática normativa) prevalece em todos os discursos, mas sim possibilite a compreensão de que existem várias possibilidades de uso da língua. Indiferentemente da passagem do aluno pela escola, ele traz consigo internalizada a gramática que estrutura o funcionamento da sua língua. A função da linguística é desenvolver, no educando, a competência da fala e da escrita, a compreensão dos aspectos morfológico, sintático, fonológico e semântico. Todo esse trabalho deve respeitar a diversidade sociocultural do aluno e as variações que a língua adquire em diversos contextos. O aluno deve compreender que existem várias formas da língua com as quais pode se expressar e perceber essas mudanças em determinados ambientes. Não é necessária tanta rigidez em empregar a norma culta, e sim mostrar para o aluno que em certas situações ele deve utilizá-la, como na elaboração de documentos oficiais.

O livro didático sempre foi organizado para o domínio do professor sobre os conteúdos que devem ser ensinados, e isso pode não corresponder às necessidades do aprendizado da língua. Quando essa correspondência não acontece, a bagagem que o aluno traz consigo do meio em que cresceu não é valorizada, a educação não é estimulada, então o aluno nada tem a acrescentar à sua formação, e sim apenas as regras da gramática normativa são consideradas o certo e aquele que não as respeita é considerado errado. Significa dizer que o conhecimento internalizado que o aluno tem da sua língua está no plano do erro, o que, hipoteticamente, significa também dizer que, num efeito dominó, seus pais falam errado, seus irmãos falam errado, as pessoas outras com quem ele se relaciona falam errado e apenas o livro didático e o professor falam certo. É um erro enxergar a realidade sociolinguística dessa forma, por isso foi escolhido o assunto sobre as variantes linguísticas como tema inicial do curso, já que identificar as diferentes linguagens e seus recursos expressivos como elementos de caracterização dos sistemas de comunicação é uma das competências exigidas do Exame Nacional do Ensino Médio (ENEM), conforme sua Matriz de Referência (BRASIL, 2009). 


\section{Considerações finais}

O contexto educacional passou muitas mudanças com a evolução tecnológica. Isso exigiu a reformulação das metodologias e ferramentas utilizadas para o ensino. Além disso, em relação às ferramentas, muitas foram incorporadas como veículo de conhecimento, exigindo capacitação do educador. Por meio dessas novas estratégias de ensino, coube ao professor um meio de levar as informações ao aluno e estimular o seu desenvolvimento, de maneira dinâmica, interagindo com o saber; que seja atraente, despertando a curiosidade do educando. É nesse momento que o Designer Instrucional deve utilizar as suas especialidades como modelador do ensino, colaborando para a efetivação do processo de ensino-aprendizagem.

O curso apresentado surgiu da necessidade de ser realizado um módulo de atualização em língua portuguesa para os servidores de uma instituição de ensino superior, atendendo ao plano de capacitação desta universidade. O mapa de atividades e a matriz de DI foram elaborados de maneira a atender as expectativas e deficiências dos técnico-administrativos em educação desta universidade.

Quando se fala em aulas de Português, é costume direcionar o pensamento para as atividades de gramática normativa (ou de conjunto de regras), somente. Isso é comum para a maioria dos participantes do curso apresentado, principalmente por terem saído da fase escolar há alguns anos. Pensando nisso, houve a preocupação em elaborar um material didático atraente e interativo, para que eles pudessem, com autonomia, fazer o próprio caminho para o conhecimento, em casa ou nas horas vagas do trabalho.

Importamo-nos com a relação inegável que há entre a língua e a vida, entre o que se pretende que seja objeto de estudo linguístico e o que precisa ser ensinado. Enxergar a língua de um ponto de vista que extrapole sua constituição estrutural e gramatical é essencial para a consecução de um ensino de língua que seja, mais do que informativo, realmente formativo e libertador. 


\section{Referências}

BRASIL. Ministério da Educação. Instituto Nacional de Estudos e Pesquisas Educacionais Anísio Teixeira. Matriz de Referência para o Enem 2009. Disponível em http://www.enem.inep.gov.br/ pdf/Enem2009_matriz.pdf, acesso em 10/5/2010. BRASIL. Ministério da Educação. Secretaria de Educação Básica. Orientações curriculares para o ensino médio: Linguagens, Códigos e suas Tecnologias. Brasília: MEC/SEB, v. 1, 2006.

BRASIL. Ministério da Educação. Secretaria de Educação Média e Tecnológica Semtec. Parâmetros Curriculares Nacionais para o Ensino Médio: Parte II - Linguagens Códigos e suas Tecnologias. Brasília: MEC/Semtec, 2002a.

BRASIL. Manual de redação da presidência da república. 2. ed., rev. e atual. Brasília: Presidência da República, 2002b. Disponível em < http://www.planalto.gov.br/ccivil_03/manual/manual.htm>. Acesso em 10 abr 2014.

E-LEARNING BRASIL. Pesquisa do perfil das iniciativas de E-Learning no Brasil 2006/2007. São Paulo: E-learning Brasil, 2008.

ENAP. e-MAG - Modelo de Acessibilidade de Governo Eletrônico: Módulo 1 - Introdução e Conceitos. Diretoria de Desenvolvimento Gerencial e Coordenação Geral de Educação a Distância. 2007.

FILATRO, Andréa. Design instrucional na prática. São Paulo: Pearson Education do Brasil, 2008.

FREITAS, Andrielly Andrade; LOYOLLA, Waldomiro; PRATES, Maurício. Linguagem e Arquitetura de Conteúdos em Educação a Distância mediada por computador. Disponível em: $<$ http://www.abed.org.br/congresso2002/trabalhos/texto03.htm>. Acesso em: 15 jun. 2010.

MIRANDA, Luísa; MORAIS, Carlos. Estilos de aprendizagem: o questionário CHAEA adaptado para língua portuguesa. Revista de Estilos de Aprendizaje. ISSN 1988-8996. 1:1. Madrid: Universidad Nacional de Educación a Distancia, 2008.

PICONEZ, S. C. B.; FILATRO, Andrea Cristina. Design Instrucional Contextualizado. In: Congresso ABED 2004, 2004, Salvador. Anais do $11^{\circ}$ Congresso Internacional da ABED 2004. São Paulo: ABED 2004, 2004. v. 1. p. 01-08.

POSSOLLI, Gabriela Eyng ; CURY, Priscila de Quadros. Reflexões sobre a elaboração de Materiais Didáticos para a Educação a Distância no Brasil. EDUCERE: IX Congresso Nacional de Educação e III Encontro Sul-brasileiro de Psicopedagogia, 2009, Curitiba. Anais do IX EDUCERE: Congresso Nacional de Educação e III Encontro Sul-brasileiro de Psicopedagogia. Curitiba: Champagnat, 2009.

ROMISZOWSKI, Hermelina Pastor. Avaliação no Design Instrucional e a Qualidade da Educação a distância: qual a relação? - Revista Brasileira de Aprendizagem Aberta e a Distância. Fevereiro, 2004.

MINAS GERAIS. Secretaria de Estado de Educação. Conteúdo Básico Comum (CBC): Língua Portuguesa - Ensinos Fundamental e Médio (Proposta Curricular). 2008.

UNIFAL-MG. Plano Anual de Capacitação. Alfenas: Universidade Federal de Alfenas, 2010. 47 p. 
